\title{
CrimRxiv
}

\section{Measuring the Temporal Stability of Near-Repeat Crime Patterns: A Longitudinal Analysis}

David Hatten ${ }^{1}$, Eric Piza ${ }^{2}$

${ }^{1}$ John Jay College of Criminal Justice, Graduate Center - CUNY,

2 John Jay College of Criminal Justice

Published on: Mar 02, 2021

License: Creative Commons Attribution-NonCommercial-NoDerivatives 4.0 International License (CC-BY-NC-ND 4.0). 


\begin{abstract}
This study investigates the temporal stability of identified near-repeat patterns using robbery crimes data in Newark, NJ. With the noteworthy exception of Hoppe \& Gerell (2019) scholars have yet to explore the temporal stability of identified spatiotemporal crime clusters. Furthermore, researchers have yet to measure the near-repeat phenomenon longitudinally. To fill this gap, the current study employs a longitudinal design to measure variation in effect size and significance of identified near-repeat crime patterns across 13 "rolling" one-year time periods within a two-year study period (2015-2016). Temporal instability was found within two out of six spatiotemporal crime clusters. Results are reported in the form of formalized descriptive statistics and visualizations of temporal trends.
\end{abstract}

\title{
Keywords:
}

Near-repeat, spatial, temporal, stability, longitudinal

\section{Citation:}

Hatten, D. and Piza, E. (2020). Measuring the Temporal Stability of Near-Repeat Crime Patterns: A Longitudinal Analysis. Crime \& Delinquency. DOI:

10.1177/0011128720922545.

\section{INTRODUCTION}

Near-repeat crime pattern studies feature a point pattern analysis that can objectively identify offenses that non-randomly cluster in space and time simultaneously. Criminologists have used near-repeat analyses to identify the spatial and temporal characteristics of spatiotemporal crime clusters in the interest of reducing repeat offending. Thus far, there have been many near-repeat crime patterns identified across crime types and geographies (Johnson et al. 2007). This generalization of near-repeat crime patterns has led to further development of what is known as the "near-repeat phenomenon" and further confirms the dynamic relationship between space and time in criminal offending. Near-repeat crime patterns differ from the more widespread hot spots analysis in that crime incidents must cluster in both space and time simultaneously, rather than solely in spatial terms (Townsley et al. 2003). Near-repeat analyses also differ from hot spots analyses in terms of the output of the analysis. Hot spots create intuitive visualizations of crime patterns whereas near-repeat analyses 
provide a rich description of future victimization risk by reporting the spatial and temporal extent of near-repeat risk for any single crime incident.

Much like the initial cross-sectional examinations of hot spots that led to the identification of crime concentrations in space (Sherman et al. 1989; Eck \& Weisburd 1995), near-repeat analyses have been solely conducted as cross-sectional or one-off observations, which makes identifying temporal stability difficult. Such cross-sectional analysis of near-repeat patterns assumes temporal stability across the entirety of a study period. For example, a recent near-repeat study of 12 years of arson incidents in Flint, Michigan by Turchan et al. (2019) identified a 252\% increase in near-repeat risk within 4 days \& 1 block of an initiator crime and that finding is assumed to hold true for each temporal portion of the study period.

To our knowledge, Hoppe \& Gerell (2019) is the only empirical examination of the temporal stability of near-repeat crime patterns. Hoppe \& Gerell (2019) reported variation of identified near-repeat crime patterns over time, with some years manifesting spatiotemporal patterns at longer spatial and temporal distances. The examination was conducted in a cross-sectional manner, reporting near-repeat risk from one calendar year to the next over six years. We build upon Hoppe \& Gerell's (2019) methodology by combining a longitudinal design with more formalized measures of temporal stability for a more comprehensive analysis of the temporal stability of near-repeat patterns. The study of hot spots was originally conducted in a cross-sectional manner until longitudinal designs were employed to test and confirm their temporal stability (Braga et al. 2010; Braga et al. 2011; Curman et al., 2015; Groff et al. 2010; Weisburd et al. 2004; Wheeler et al., 2016). We believe that a similar shift towards longitudinal research will uncover important insights as to the state of temporal stability in near-repeat crime patterns.

Our study represents the first longitudinal examination focused on assessing the temporal stability of identified near-repeat robbery patterns, using Newark, NJ as our study area. Our longitudinal design is based on "rolling" time periods that consist of every 12-month period within the two-year study time frame (January 2015 to December 2016) for a total of 13 periods. Using every time period as a unique observation for each identified near-repeat pattern, we track any variation in risk or significance of identified near-repeat patterns to inform our assessment of temporal stability. Findings of the current study indicate that one-third (two out of six) of all identified near-repeat crime patterns exhibited temporal instability. We propose that the methodology and analytical approach we employ in this study may be used as a 
template for future examinations of new crime types and geographies to make a more definitive judgement of the temporal stability of the near-repeat phenomenon. In addition, the current study provides a way to visualize the temporal stability of nearrepeat patterns in a way that allows for the identification of patterns that are suitable for informing police interventions.

\section{LITERATURE REVIEW}

Near-repeat analyses identify criminal offending patterns where the spatial and temporal coincidence of crime incidents are too close in proximity to be the result of a random pattern of events (Townsley et al. 2003). This dynamic relationship is consistent with repeat offending or repeat victimization (Farrell \& Pease 1994; Pease 1998). Repeat offenders reliably act in such temporal and spatial coincidence that criminologists have coined the term "near-repeat phenomenon" to describe their behavior. According to the near-repeat phenomenon, once a place or person has been victimized, the risk of future victimization for nearby places or people increases but later decreases as time passes (Johnson \& Bowers 2004; Townsley et al. 2003).

Criminologists have proposed two hypotheses to help explain the underlying criminal activity that leads to near-repeat patterns: the "boost" and "flag" hypotheses. In the "boost" scenario, the subsequent crime is less likely without the initial crime; in other words, the first crime increases the risk of a subsequent crime (Pease 1998). Bowers \& Johnson (2004) hypothesize that this conditional relationship is due to the sharing of experiential knowledge between overlapping offenders or offender groups. In the "flag" scenario, the crime occurs because there was some inherent characteristic to the place or person. In other words, they have been "flagged" or made attractive to potential offenders (Pease 1998). Researchers have also referred to the flag hypothesis as the "risk heterogeneity" perspective (Johnson \& Bowers 2004). This perspective assumes a time-stable variation in perceptible risk across the landscape, which functions according to the characteristics of the places in those areas (Johnson 2008) and creates a predictable distribution of crimes over time.

Studies of burglary patterns provided the first empirical validations of the near-repeat phenomenon (Bediroglu et al. 2018; Bernasco 2008; Chainey \& Da Silva 2016; Hino \& Amemiya 2019; Johnson et al. 2007; Johnson et al. 2009; Moreto et al. 2014; Nobles et al. 2016; Short 2009; Townsley et al. 2003). Scholars have recently extended the nearrepeat concept to several crime types, including shootings, gun assaults, and hand grenade attacks (Loeffler et al. 2017; Ratcliffe \& Rengert 2008; Sturup et al. 2017; Sturup et al. 2019; Wells \& Wu 2012), insurgent attacks in Iraq (Townsley et al. 2008), 
motor vehicle theft (Block \& Fujita 2013; Johnson et al. 2009, Lockwood 2012; Piza \& Carter 2018), and arson (Grubb \& Nobles 2016). Research has further observed nearrepeat crime patterns across multiple crime types within single study areas, such as in Campinas, Brazil (Melo et al. 2018).

Near-repeat studies of robbery, the crime type used in the current study, have not occurred as frequently as spatiotemporal studies of other crime types, particularly burglary. However, like other crime types, robbery has consistently exhibited nearrepeat patterns (Glasner et al. 2016; Grubesic \& Mack 2008; Haberman \& Ratcliffe 2012; Youstin et al. 2011; Zhang et al. 2015). Near-repeat analyses vary in terms of the temporal bandwidths in which spatiotemporal clustering is measured, including 7-day (Melo et al. 2018), 6-day (Zhang et al. 2015), 4-day (Grubesic \& Mack 2008; Youstin 2011), and 1-day (Haberman \& Ratcliffe 2012; Youstin et al. 2011). According to these findings, one robbery follows another in quick succession and are close in spatial distance exhibiting a "spree-like" quality (Haberman \& Ratcliffe (2012). However, as all these studies were cross-sectional, it is still unclear whether these spree-like patterns consistently repeat themselves over time.

It is helpful to consider the evolution of the hot spot analysis literature, given that scholars often describe near-repeat analysis as an extension of hot spot analysis, due to its ability simultaneously account for spatial and temporal concentrations (Piza and Carter, 2018: p. 843). Early examinations of hot spots were cross sectional in nature with limited capacity to support conclusions concerning temporal stability (Eck \& Weisburd 1995; Sherman et al. 1989). Over time, hot spots research expanded to longitudinal examinations and found that there was a significant amount of temporal stability of identified hot spots (Braga et al. 2010; Braga et al. 2011; Groff et al. 2010; Weisburd et al. 2009; Weisburd et al. 2004). This cumulative body of literature indicates that crime concentrates in space and at a small number of places that are time-stable and account for a relatively large proportion of the crime for any larger area (Weisburd 2015). Conversely, researchers have previously found that near-repeat events have a mixed or muddled relationship with hot spot generation and growth (Haberman \& Ratcliffe 2012; Wang et al. 2017). Said differently, areas where crime spatially clusters does not always simultaneously cluster in terms of time. Therefore, even though hot spots typically exhibit significant temporal stability over time (Braga et al. 2010; Braga et al. 2011; Curman et al., 2015; Groff et al. 2010; Weisburd et al. 2004), this assumption cannot extend to the results of near-repeat crime pattern analyses. 
While near-repeat patterns have been observed across a large array of study settings and crime types, whether these patterns remain constant or vary over time has not been subjected to empirical examination. A noteworthy exception is the recent study by Hoppe \& Gerell (2019), which conducted a near-repeat analysis of burglary over a six-year time frame (2009-2014) in Malmö, Sweden. Hoppe \& Gerell (2019) found that the observed risk values and associated significance levels varied among the individual component years of the study period and in contrast to the risk reported for the entire study period. For example, observed risk of a near-repeat event within a week and 301-400 meters of the first event ranged from a 0-70\% increase across the six individual time periods, whereas it was a 33\% increased risk when the study period was analyzed in full. In other words, there was a year to year change in risk associated with that spatiotemporal relationship and any individual year exhibited different levels of risk than the full six-year study period.

The question of near-repeat stability within the same study setting and time frame, which has yet to be explored in the near-repeat literature, is the focus of the current study. Recently, near repeat examinations have increased in the length of their study periods ranging from five years (Bediroglu et al. 2018; Glasner et al. 2016; Sturup et al. 2017) to 12 years (Turchan et al. 2019). Such studies greatly contribute to the nearrepeat literature by increasing the reliability of the identified near repeat crime patterns due to the law of large numbers (Johnson et al. 2007). However, the increase in data points does not directly inform the issue of temporal stability due to the use of cross-sectional rather than longitudinal designs that allow for the identification of trends over time. This issue was first raised by Hoppe \& Gerell (2019) and serves as the foundation of the current study.

\section{SCOPE OF THE CURRENT STUDY}

We assess whether there is any variation in the significance and magnitude of nearrepeat crime patterns within the confines of a single study period and study setting. Hoppe \& Gerell (2019) first reported the temporal instability of near-repeat patterns but employed a cross-sectional design that was not focused on examining stability of patterns. The longitudinal design employed in this study, using rolling time periods, allows us to track variation of the previously identified near-repeat patterns, the patterns being the focus of the study. Using the results of our analysis we include visualizations of the variation in risk and associated significance test results along with suggested subgroups or typologies of temporal trends we observed. Our study uses 
robbery crime data from Newark, NJ but we propose that this framework we use for assessing temporal stability of near-repeat patterns may be used in any context.

\section{STUDY SETTING}

The current study focuses on robbery incidents occurring in Newark, NJ from January $1^{\text {st }}, 2015$ to December 31 $1^{\text {st }}, 2016$. Newark is the largest city in terms of population in the State of New Jersey and is the administrative center of Essex County. During the study period, the Census Bureau's American Community Survey (ACS) estimates the total population at 279,793 with an adult population (age 18 and over) of 208,754. Median household income was \$34,826 compared to \$57,652 nationwide, with $28.30 \%$ of all Newark residents under the poverty line compared with $12.30 \%$ for the United States as a whole. African Americans and Hispanics comprise $48.30 \%$ and $35.60 \%$ of the population, respectively $\underline{1}$.

The Newark Police Department (NPD) reported 1826 robberies in 2015 (Jan $1^{\text {st }}$ December $31^{\text {st }}$ ) and 1412 robberies in 2016 (Jan $1^{\text {st }}$ - December $31^{\text {st }}$ ) for a total of 3238 cases and representing a $22.67 \%$ reduction in reported robberies year over year. Similar reductions were seen at both the county level as Essex County reported a $20.79 \%$ drop (2900 to 2297), and the State of New Jersey, an 8.31\% drop (9743 to 8933)르. The City of Newark accounts for $17.3 \%$ of robberies state-wide and at its lowest rate (in 2016) still reports 504 robberies per 100,000 residents which is over 5 times the nation-wide average for this time period $(102.8$ robberies per 100,000$) \underline{3}$. Robbery trends over the study period vary slightly from month to month, with peaks in spring and summer, but show a slight reduction overall. For this reason, Newark is an ideal environment to study the near-repeat phenomenon, particularly with robbery, due to the consistently high rates of robbery which provides for a suitable study size and easy availability of valid spatially referenced data.

Data were provided by the CompStat unit of the NPD. Researchers geocoded all robbery incidents to street centerlines using a 20 -foot side offset and end offset of $3 \%$ via a dual-range addresses address locator in ArcGIS 10.4.1. We achieved a match rate of $98.5 \%$, well above the minimum geocoding rate of $85 \%$ recommended by previous studies (Andresen et al. 2020; Ratcliffe 2004) as well as above the more stringent requirements proposed in a more recent study (Briz-Redon et al. 2019). After removing the 51 cases we were unable to geocode, our final dataset contains 3187 total robberies $\underline{4}$ in the two-year study period. Crime incidents were projected into NAD 
1983 State Plane New Jersey FIPS 2900 Meters and the near-repeat analysis conducted distance measures and report results in terms of Meters.

\section{ANALYTICAL APPROACH}

Given the findings from previous empirical examinations, most notably Hoppe \& Gerell (2019), we propose three hypotheses that guide our analytical strategy.

Hypothesis 1: Near Repeat patterns will vary in terms of risk over time

Hypothesis 2: Near Repeat patterns will vary in terms of reliability over time

Hypothesis 3: Near Repeat patterns can be divided into easily discernible subgroups based on their longitudinal trends

To address these hypotheses, we propose a multi-step analytical approach that begins by first identifying the correct spatial and temporal parameters to search for near repeat patterns in Newark, NJ.

\section{Near-repeat Analysis}

We test for near-repeat robbery patterns using the Near Repeat package in $\mathrm{R}$ Version 1.1.456 (Steenbeek 2018). The Near Repeat package uses the Knox Test to identify and describe spatiotemporal crime and victimization patterns for a given crime incident database as well as report the risk of future victimization. George Knox (1964) first developed the Knox Test to study the spatiotemporal patterning of diseases. Observed counts of events are compared to randomly distributed counterfactuals (expected counts) to identify spatiotemporal clusters. The Near Repeat package first compares the observed pattern of spatiotemporal relationships between all points with the results of the same analysis with the dates of the crime events randomly reassigned to create a counterfactual (Steenbeek 2018). The integration of the MonteCarlo simulation process allows for this procedure to be repeated a user specified number of times and generate p-values that attest to the pattern's reliability (Johnson et al. 2007). For example, to achieve a significance of p-value <.001, the spatiotemporal pattern observed would be expected to occur by chance only once in 1000 times.

Significance of near-repeat patterns is determined based on the results of the MonteCarlo process and reported in the form of p-values. Risk of future offending is reported in the form of Knox ratios. Knox ratios are the ratio of the observed number of "nearrepeat pairs", or crimes linked in space and time, in each space-time band, to the expected number of near-repeat pairs given a random distribution of crimes. Knox 
Ratios above 1 are indicative of near-repeat patterns and represent an increased risk of future offending for that space-time band. Though, Ratcliffe (2009) notes that a Knox Ratios should exhibit statistical significance $(p .<0.05)$ and be 1.20 or greater (i.e. at least $20 \%$ greater than we would expect by chance) for crime to be considered truly overrepresented and, thus, a spatiotemporal cluster.

\section{Exploratory Data Analysis}

We begin our study by identifying the spatial and temporal parameters with the greatest magnitudes of risk, as measured by Knox Ratios. Our near-repeat model parameters are informed by prior near-repeat studies that have used a range of temporal bands, including 1 day (Turchan et al., 2019) , 4 days (Grubesic \& Mack, 2008; Youstin et al., 2011 ), 7 days (Braithwaite \& Johnson, 2012; Haberman \& Ratcliffe, 2012 ), and 14 days (Johnson et al., 2007; Ratcliffe \& Rengert, 2008 ). Many studies have conducted near-repeat analysis across multiple temporal bands, which allows researchers to identify when an observed near-repeat pattern is most salient. For example, significant clustering during the 4-day period but not the 7-day period would suggest that the near-repeat pattern is best operationalized as 4-day phenomena (Piza \& Carter, 2018). We followed such an approach in the current study.

We based our spatial bandwidth on the average street segment length for the City of Newark (137.77 meters), as measured in ArcGIS 10.4. To measure distance between points, we used the Manhattan distances technique, the default setting for the Near Repeat package. Where Euclidean distances are calculated based on the shortest distance between two x/y coordinates on a grid, Manhattan distances more closely approximate the distances of true travel patterns following a street grid (Chainey \& Ratcliffe 2005; Rossmo 2000).

The exploratory near-repeat analysis concerns the entire two-year time frame from January 2015 - December 2016. The goal of this analysis is to identify the parameters whereby the greatest number of near-repeat crime patterns $(p .<0.05$ and Knox Ratio $>=1.20$ ) are identified among spatiotemporal relationships. We restrict the number of spatial and temporal bands to seven and five, respectively. Restricting the number of spatial and temporal bands is more substantively parsimonious as we are unlikely to find patterns outside those ranges as per the near-repeat phenomenon. The restriction of bands is also computationally efficient and results in less time to generate risk values. To further restrict the analysis, we focus on near-repeat crime patterns in the two-year period that have a significance level of $p$-value $<.001$ as these are the most reliable in terms of statistical significance and least likely to be the result of chance. 
The results of this exploratory analysis serve as the foundation for the subsequent stability analysis.

\section{Stability Analysis}

To test for stability in near-repeat patterns, we first convert the full two-year study period into rolling year-long windows. The first rolling time period extended from January 2015 through December 2015, the second time period extended from February 2015 through January 2016, etc. This results in 13 time periods, or observations, across the 24-month study period. By breaking up the time periods in this way we minimize the potential for arbitrary temporal edge effects by accounting for any administrative or seasonal changes while still assuring there is enough data to not be artificially influencing risk values and the determination of significance of nearrepeat patterns (Johnson et al. 2007).

We then conduct a near-repeat analysis on each of the 13-rolling year-long time periods using with the same spatial and temporal parameters as identified in the exploratory analysis. We then record the results of the near-repeat analyses conducted for each one of the rolling time periods, focusing on the six spatiotemporal relationships that we found exhibited the most reliable near-repeat patterns in the twoyear study period (which will be discussed further in the results). This process creates a total of 78 observations. The resulting Knox ratios and their p-values were then plotted alongside one another to visualize the changes in risk and significance over time.

\section{Measures of Temporal Stability}

We judge temporal stability using three measures. The first is a formalization and expansion on the results of Hoppe \& Gerell (2019) where we document the stability of effect size based on the resultant summary statistics and directly addresses our first research hypothesis. We calculate the mean Knox Ratio value, range of Knox Ratio values, and the corresponding width of range differences across all 13 rolling time periods. In terms of Knox Ratio values, the larger the range difference value, the wider the range, and the greater the instability of effect size.

The second and third measures focus on the stability of significance for identified nearrepeat patterns and address our second research hypothesis. For all six significant spatiotemporal relationships, we report both the proportion of time periods that keep the same level of significance as the two-year study period ( $p$-value $<.001$ ) as well as 
the proportion of time periods that drop to lower significance levels ( $\mathrm{p}$-value <.05). For each spatiotemporal crime cluster, the greater the proportion of time periods where significance standards meet the more stringent significance threshold $(p<0.01)$, the more temporally stable. Conversely, the greater the proportion of time periods where significance standards need to be relaxed or where there are null findings, the greater the temporal instability of significance.

\section{Typologies of Temporal Stability}

The final part of this study addresses our third research hypothesis and focuses on the visualization of the results of our analysis. We produced a series of visualizations consisting of the observed Knox ratio values, and their associated significance test results, for 13 time periods across all six significant spatiotemporal relationships. Using these graphics, we identified four unique subgroups or typologies of temporal trends that provide further nuance to the description of near repeat crime patterns longitudinal trends. These trends include Stable (no discernible variation in risk or significance), Stable - Increasing (where risk increases over time), Stable - Decreasing (where risk decreases over time), and Unstable (where risk and significance vary without discernible pattern). Reported along with the measures of temporal stability we aim to give a holistic understanding of the variation and reliability of reported risk as well as identify potential subgroups of temporal trends.

\section{RESULTS}

\section{Exploratory Data Analysis}

Table 1 displays the results of the exploratory near-repeat analyses. Near-repeat crime patterns that fit our criteria were identified at only the repeat victimization (first temporal window and same location) space-time band for both the 14-day and 7-day temporal bandwidths. The 4-day temporal bandwidth identified near-repeat crime patterns that fit our criteria across three space-time bands: within 4 days $\&$ same location, within 4 days \& 2 blocks, and within 4 days \& 3 blocks. Risk values increased as the time bands narrowed to the 1-day temporal bandwidth (see Table 1), suggesting that increased levels of risk in longer time frames were being driven by crime activity and dynamics operating at much shorter temporal relations as suggested by Johnson et al. (2007).

In addition to assessing change in risk values across temporal bandwidths, we assessed whether identified near-repeat patterns were unique to specific temporal 
bandwidths. All but one near-repeat pattern reported for the longer temporal bandwidths was also reported at the 1-day temporal bandwidth (4-day bandwidth, within 4-days \& 3 blocks). However, the 1-day temporal bandwidth not only exhibited a greater number of near-repeat patterns that fit our criteria but exhibited consistently higher levels of risk across like spatiotemporal relationships than the longer temporal bandwidths. For example, a near-repeat pattern was identified in the 4-day temporal bandwidth within 4 days and 2 blocks of the incident (Knox Ratio $=1.23$ ) that was also reported in the 1 -day temporal bandwidth but at 1 day and 2 blocks (Knox Ratio $=$ 1.80). If we relied upon the analysis that used the longer temporal bandwidth (4-day), we would be underestimating the risk by $57 \%$ in addition to providing less specific information as to where in time the risk is exhibited. After taking into consideration the results of the different temporal bandwidths, we focused on the 1-day temporal bandwidth.

Table 1. Near Repeat Analysis Knox Ratios (2-Year Analysis from 2015-2016)

\begin{tabular}{|c|c|c|c|c|c|}
\hline 1 DAY & & & & & \\
\hline TIME & 0 to 1 days & 1 to 2 days & 2 to 3 days & 3 to 4 days & 4 to 5 days \\
\hline DISTANCE & & & & & \\
\hline $\begin{array}{l}\text { Same } \\
\text { location }\end{array}$ & $9.03 * *$ & $2.79 *$ & $2.97^{*}$ & 1.82 & $2.27 *$ \\
\hline 1 Block & $2.65^{* *}$ & 0.94 & 0.86 & 1.21 & 1.00 \\
\hline 1 - 2 Blocks & $1.80^{* *}$ & 1.13 & 1.09 & 1.15 & 1.01 \\
\hline 2 - 3 Blocks & 1.13 & 1.09 & $1.17 *$ & $1.38^{* *}$ & 1.12 \\
\hline 3 - 4 Blocks & $1.30^{*}$ & $1.31^{* *}$ & 0.93 & 1.09 & 1.00 \\
\hline $4-5$ Blocks & $1.54 * *$ & 1.08 & 1.15 & 1.00 & 1.08 \\
\hline $5-6$ Blocks & $1.20 *$ & 1.02 & 1.00 & 0.96 & 1.06 \\
\hline 4 DAYS & & & & & \\
\hline TIME & 0 to 4 days & 5 to 8 days & $\begin{array}{l}9 \text { to } 12 \\
\text { days }\end{array}$ & $\begin{array}{l}13 \text { to } 16 \\
\text { days }\end{array}$ & $\begin{array}{l}17 \text { to } 20 \\
\text { days }\end{array}$ \\
\hline
\end{tabular}




\begin{tabular}{|c|c|c|c|c|c|}
\hline \multicolumn{6}{|l|}{ DISTANCE } \\
\hline $\begin{array}{l}\text { Same } \\
\text { location }\end{array}$ & $3.69 * *$ & $1.67 *$ & 1.23 & $1.78^{*}$ & 1.31 \\
\hline 1 Block & $1.25^{*}$ & 1.17 & $1.18^{*}$ & 0.97 & 1.14 \\
\hline 1 - 2 Blocks & $1.23^{* *}$ & 0.99 & $1.14^{*}$ & $1.16^{*}$ & 1.06 \\
\hline 2 - 3 Blocks & $1.20^{* *}$ & $1.12^{*}$ & 1.06 & 1.04 & 0.96 \\
\hline 3 - 4 Blocks & $1.15^{* *}$ & $1.09 *$ & $1.11 *$ & 0.95 & 1.03 \\
\hline $4-5$ Blocks & $1.15^{* *}$ & 1.03 & 1.02 & 0.97 & 1.07 \\
\hline $5-6$ Blocks & 1.03 & $1.09 *$ & 1.06 & $1.08 *$ & 0.94 \\
\hline \multicolumn{6}{|l|}{7 DAYS } \\
\hline TIME & 0 to 7 days & $\begin{array}{l}8 \text { to } 14 \\
\text { days }\end{array}$ & $\begin{array}{l}15 \text { to } 21 \\
\text { days }\end{array}$ & $\begin{array}{l}22 \text { to } 28 \\
\text { days }\end{array}$ & $\begin{array}{l}29 \text { to } 35 \\
\text { days }\end{array}$ \\
\hline \multicolumn{6}{|l|}{ DISTANCE } \\
\hline $\begin{array}{l}\text { Same } \\
\text { location }\end{array}$ & $2.62^{* *}$ & $1.49 *$ & $1.49 *$ & 0.86 & 1.10 \\
\hline 1 Block & $1.18^{*}$ & $1.15^{*}$ & 1.10 & 1.02 & $1.17 *$ \\
\hline 1 - 2 Blocks & $1.11 *$ & $1.13 *$ & 1.08 & 0.95 & 1.07 \\
\hline 2 - 3 Blocks & $1.16^{* *}$ & 1.06 & 1.02 & $1.07 *$ & 1.03 \\
\hline 3 - 4 Blocks & $1.10 * *$ & $1.08 *$ & 0.99 & 1.04 & 0.98 \\
\hline 4 - 5 Blocks & $1.10 * *$ & 1.01 & 1.01 & $1.06 *$ & 0.97 \\
\hline 5 - 6 Blocks & 1.05 & $1.06^{*}$ & 0.98 & 0.98 & 0.99 \\
\hline \multicolumn{6}{|l|}{14 DAYS } \\
\hline TIME & $\begin{array}{l}0 \text { to } 14 \\
\text { days }\end{array}$ & $\begin{array}{l}15 \text { to } 28 \\
\text { days }\end{array}$ & $\begin{array}{l}29 \text { to } 42 \\
\text { days }\end{array}$ & $\begin{array}{l}43 \text { to } 56 \\
\text { days }\end{array}$ & $\begin{array}{l}57 \text { to } 70 \\
\text { days }\end{array}$ \\
\hline
\end{tabular}




\begin{tabular}{|l|l|l|l|l|l|}
\hline DISTANCE & & & & & \\
\hline $\begin{array}{l}\text { Same } \\
\text { location }\end{array}$ & $\mathbf{2 . 0 8 * *}$ & 1.18 & 1.25 & $1.35^{*}$ & 0.83 \\
\hline 1 Block & $1.17^{* *}$ & 1.06 & $1.17^{* *}$ & 1.07 & 0.96 \\
\hline $1-2$ Blocks & $1.13^{* *}$ & 1.02 & $1.07^{*}$ & 1.05 & 0.99 \\
\hline $2-3$ Blocks & $1.11^{* *}$ & 1.05 & 1.04 & $1.07 *$ & 0.98 \\
\hline $3-4$ Blocks & $1.09^{* *}$ & 1.02 & 0.99 & 0.97 & 0.99 \\
\hline $4-5$ Blocks & $1.05^{*}$ & $1.04 *$ & 1.02 & 1.01 & 0.98 \\
\hline $5-6$ Blocks & $1.06^{*}$ & 0.98 & 0.99 & 1.01 & 0.99 \\
\hline
\end{tabular}

Using the 1-day temporal bandwidth parameter we identified six space-time bands where near-repeat crime patterns were found: 1 day \& same location (i.e., repeat victimization), within 1 day \& 1 block, 1 day \& 2 blocks, 1 day \& 5 blocks, 2 days \& 4 blocks, and 4 days \& 3 blocks. Near-repeat analyses were then conducted across all 13 "rolling" time periods and we reported Knox ratio values and significance test results for all six space-time bands.

Stability Analysis

Table 2 reports the results from our temporal stability analysis conducted on all six identified near-repeat patterns across 13 time periods. The first three columns report descriptive statistics for each space-time band, including the mean, range, and range width of Knox Ratio values across the 13 rolling time periods. In the subsequent two columns, we recorded the proportion of time periods that continue being significant at $p$-value $<.001$ and the proportion of time periods that continue being significant but at $p$-value $<.05$. Finally, based on the observed trend in risk over time, we designated which typology best described the near-repeat pattern.

Table 2. Stability Statistics for all Spatiotemporal Relationships Across Time Periods 


\begin{tabular}{|c|c|c|c|c|c|c|}
\hline $\begin{array}{l}\text { Space- } \\
\text { Time Band }\end{array}$ & $\begin{array}{l}\text { Mean Knox } \\
\text { Ratio Value }\end{array}$ & $\begin{array}{l}\text { Knox Ratio } \\
\text { Value } \\
\text { Range }\end{array}$ & $\begin{array}{l}\text { Knox Ratio } \\
\text { Range } \\
\text { Width }\end{array}$ & $\begin{array}{l}\text { Percent } \\
\text { Stable (p- } \\
\text { value < } \\
.001)^{* *}\end{array}$ & $\begin{array}{l}\text { Percent } \\
\text { Stable (p- } \\
\text { value } \\
<.05)^{* *}\end{array}$ & $\begin{array}{l}\text { Temporal } \\
\text { Typology }\end{array}$ \\
\hline $\begin{array}{l}1 \text { Day } \& \\
\text { Same } \\
\text { Location }\end{array}$ & 4.04 & $(5.15-0.99)$ & 4.16 & $38.46 \%$ & $92.31 \%$ & Unstable \\
\hline $\begin{array}{l}1 \text { Day \& } 1 \\
\text { Block }\end{array}$ & 2.58 & $(2.92-2.21)$ & 0.71 & $92.31 \%$ & $100.00 \%$ & Stable \\
\hline $\begin{array}{l}1 \text { Day \& } 2 \\
\text { Blocks }\end{array}$ & 1.50 & $(2.30-1.06)$ & 1.24 & $23.08 \%$ & $53.85 \%$ & Unstable \\
\hline $\begin{array}{l}1 \text { Day \& } 5 \\
\text { Blocks }\end{array}$ & 1.57 & $(1.89-1.26)$ & 0.63 & $61.54 \%$ & $100.00 \%$ & $\begin{array}{l}\text { Stable - } \\
\text { Increasing }\end{array}$ \\
\hline $\begin{array}{l}2 \text { Days \& } 4 \\
\text { Blocks }\end{array}$ & 1.42 & $(1.62-1.27)$ & 0.35 & $84.62 \%$ & $100.00 \%$ & $\begin{array}{l}\text { Stable - } \\
\text { Decreasing }\end{array}$ \\
\hline $\begin{array}{l}4 \text { Days \& } 3 \\
\text { Blocks }\end{array}$ & 1.35 & $(1.50-1.23)$ & 0.27 & $23.08 \%$ & $100.00 \%$ & $\begin{array}{l}\text { Stable - } \\
\text { Increasing }\end{array}$ \\
\hline
\end{tabular}

*This is our first measure of stability in terms of the level of identified risk of robbery. The wide the range, the less stable the exhibited risk is across all time periods.

**These are our measures of the temporal stability of near repeat crime pattern as they relate to significant identified crime patterns. Those space-time bands with higher proportion of time periods exhibiting the same level of significant risk values are more stable than those where the previously identified risk is no longer significant as a result of the Monte Carlo process.

In the 1 day \& same location space-time band, we found moderate temporal instability due to the wide range of reported risk values and the loss of significance in one out of the 13 time periods (see Table 2). Mean risk of future offending across all 13 time periods was highest for Robbery in the 1 day \& same location space-time band (Knox Ratio $=4.04)$, this figure represents a $304 \%$ increased risk of robbery. This space-time band had the least stability in effect size as the range (5.15-0.99) and widest range 
width of all space-time bands (Range Width $=4.16$ ). Time period 13 (January 2016 December 2016) marked a substantial departure in terms of estimated risk of future robbery (Knox Ratio $=0.99$ ) and a lack of significance at any level (null). Less than half (38.46\%) of all time periods continue being significant at $p$-value $<.001$ and all but one $(92.31 \%)$ time period retains significance at the more relaxed standard of $\mathrm{p}$-value<.05. As less than half of all time periods retained significance at the $\mathrm{p}$-value $<.001$ standard including one time period that lacked significance entirely, this space-time band exhibited a lack of stability in significance. In Figure 1, we visualize the results of this Unstable space-time band and contrast it with the following space time band, 1 day \& 1 block, as an example of the differences between Stable and Unstable typologies.

Within the 1 day \& 1 block space-time band there was little to no temporal instability. Risk of future robberies remained high across all 13 time periods with the second highest mean risk reported (Knox Ratio $=2.58$ ), representing a $158 \%$ increased risk of future robbery. The 1 day \& 1 block space-time band's range (2.91-2.21) had a correspondingly low range width (.71), suggestive of stability in effect size. The 1 day \& 1 block space-time band exhibited remarkable stability in significance. This spacetime band had the highest proportion of time periods that retained significance at the $\mathrm{p}$-value $<.001$ level $(92.31 \%)$ and when that standard is relaxed to $\mathrm{p}$-value $<.05$, all time periods were significant. The results from this space-time show exceptional temporal stability band and offers a stark contrast to the previous space-time band in terms of both stability of effect size and significance (See Figure 1).

Figure 1 - Near Repeat Temporal Stability Typologies - Stable vs. Unstable 
1 day $\&$ same location vs. 1 day $\& 1$ block

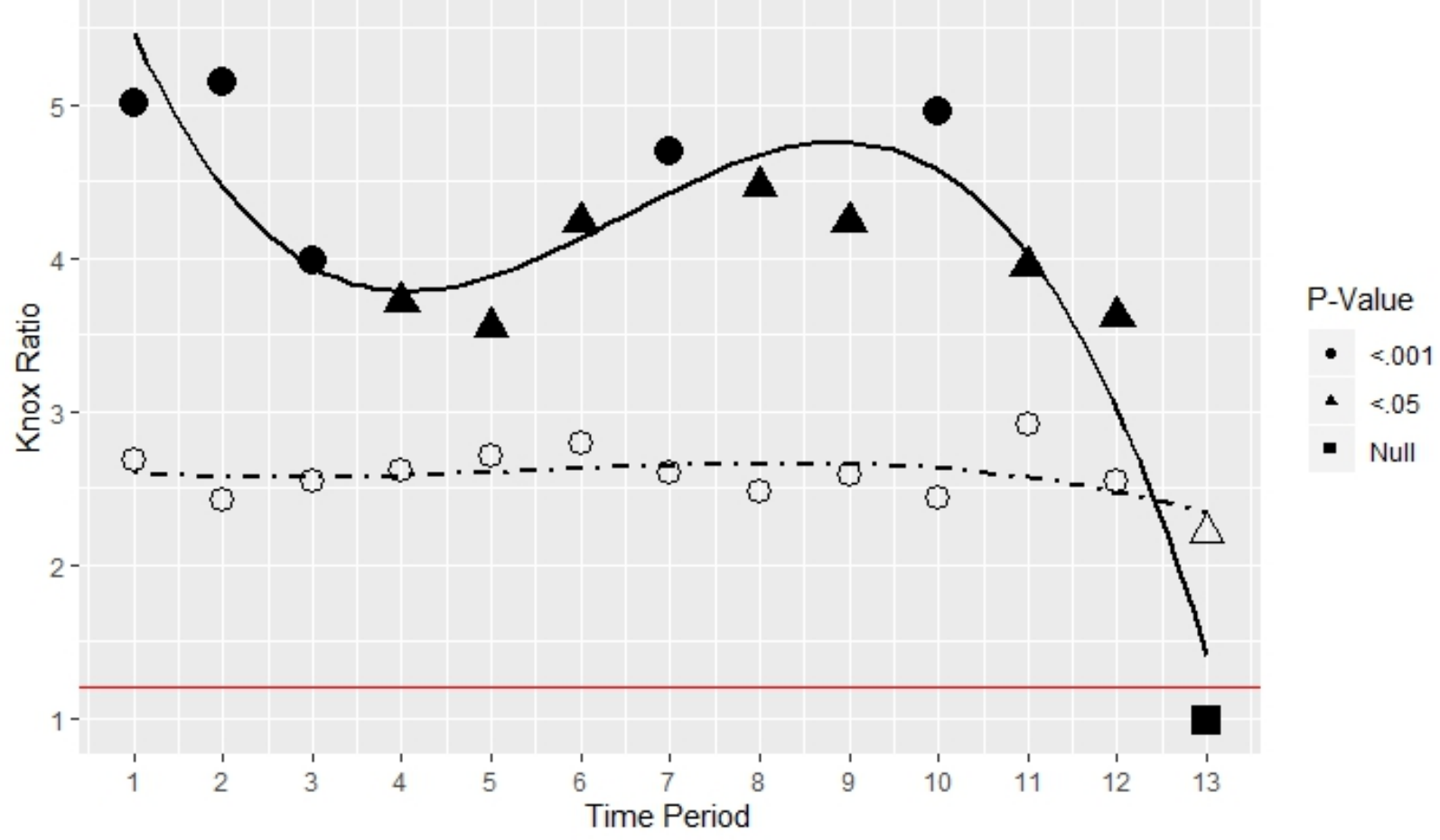

*Solid line is 1 day \& same location and Checkered line is 1 day \& 1 block

**Solid Red Line represents Knox Ratio $=1.20$

The 1 day \& 2 blocks space-time band exhibited severe temporal instability. Mean risk $($ Knox Ratio $=1.50)$ was relatively low with the second widest range (2.30-1.06) and corresponding range width (1.26) of all space-time bands, suggestive of a lack of stability in effect size. The 1 day \& 2 blocks space-time band also exhibited very little stability in significance as it was tied for the lowest proportion of time periods that retained significance at the p-value $<.001$ level (15.38\%) and, more importantly, had the lowest proportion significant at the p-value<.05 level (53.85\%). In addition, Knox ratios failed to achieve statistical significance in six time periods, including Time Periods 1 (January 2015 - December 2015), 6 (June 2015 - May 2016), 7 (July 2015 June 2016), 8 (August 2015 - July 2016 ), 9 (September 2015 - August 2016), and 10 (October 2015 - September 2016). Figure 2 best displays this lack of stability of effect size and significance and contrasts it with the Stable - Increasing typology identified in space-time band 1 day \& 5 blocks.

Figure 2 - Near Repeat Temporal Stability Typologies - Unstable vs. Stable Increasing 
1 day $\& 2$ blocks vs. 1 day $\& 5$ blocks

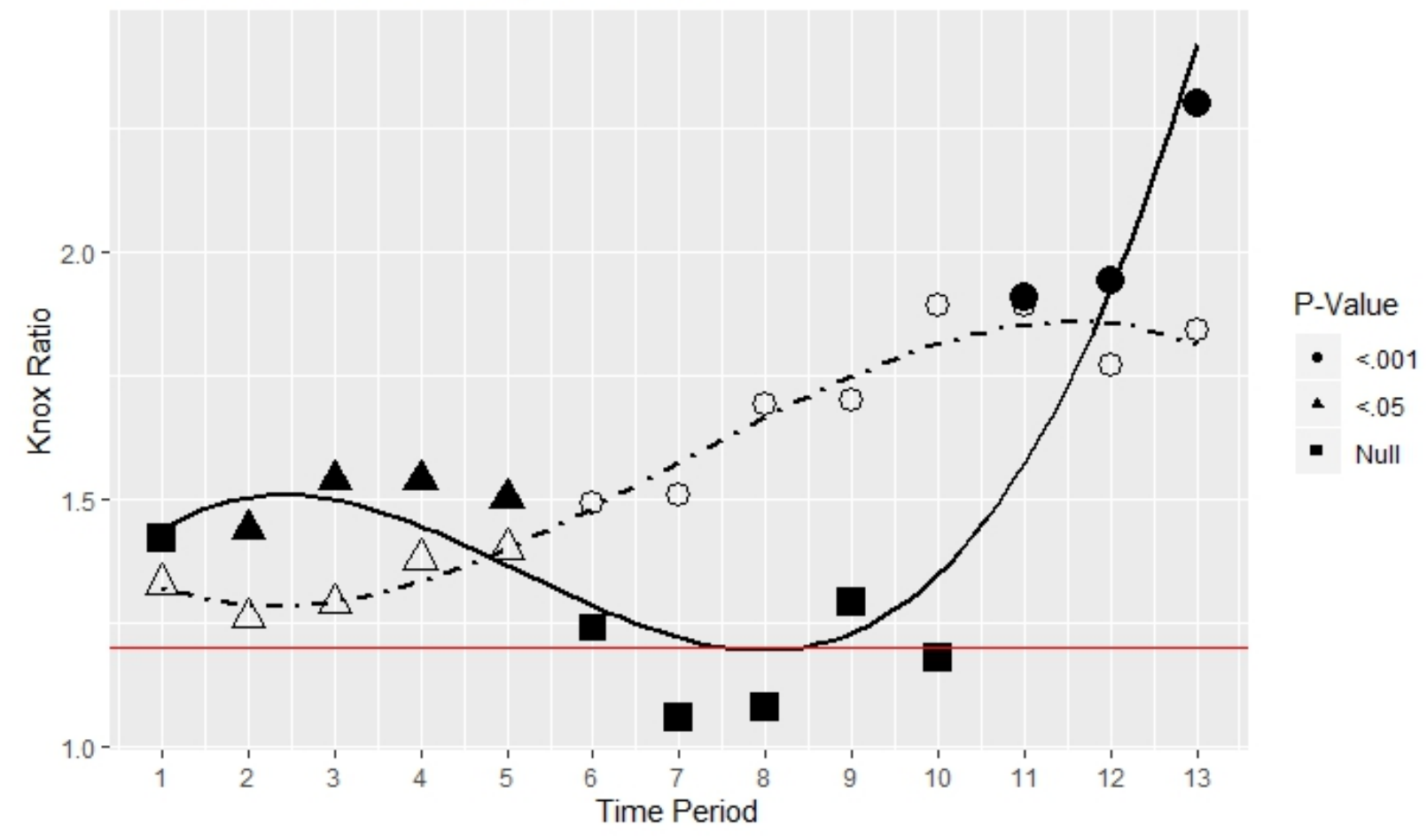

*Solid line is 1 day \& 2 blocks and Checkered line is 1 day \& 5 blocks

**Solid Red Line represents Knox Ratio $=1.20$

Minimal to no temporal instability was found in the 1 day \& 5 block and 2 days \& 4 blocks space-time bands. The 1 day \& 5 blocks and 2 days $\& 4$ blocks space-time bands reported similar levels of mean future risk of robbery over the 13 rolling time periods (Knox Ratio $=1.57$, and 1.42, respectively). The 1 day and 5 blocks space-time band reported a narrow range (1.91-1.26) and small range width (Range Width $=.63$ ), suggesting stability in effect size. The 2 days $\& 4$ blocks space-time band also exhibited stability in effect size as it had the second lowest range width value (Range Width $=.35$ ) and a similarly narrow range (1.62-1.27). Both the 1 day \& 5 blocks and 2 day \& 4 block space-time bands were similarly stable in significance, as each found significance near-repeat crime patterns for $100 \%$ of time periods at $\mathrm{p}$-value $<.05$ with similar results at p-value $<.001$ ( $61.54 \%$ and $84.62 \%$, respectively). Where these spacetime bands differ is in the visualization of results. Specifically, the 1 day \& 5 blocks space-time band shows a steady increase in risk over time and as such was deemed a Stable - Increasing pattern (See Figure 2). Figure 3 displays the 2-day \& 4 blocks space-time band as stable but decreasing in terms of risk over time, a Stable Decreasing pattern, and is contrasted with the final space-time band that exhibited Stable - Increasing pattern. 
Figure 3 - Near Repeat Temporal Stability Typologies - Stable - Decreasing vs. Stable - Increasing

2 days $\& 4$ blocks vs. 4 days $\& 3$ blocks

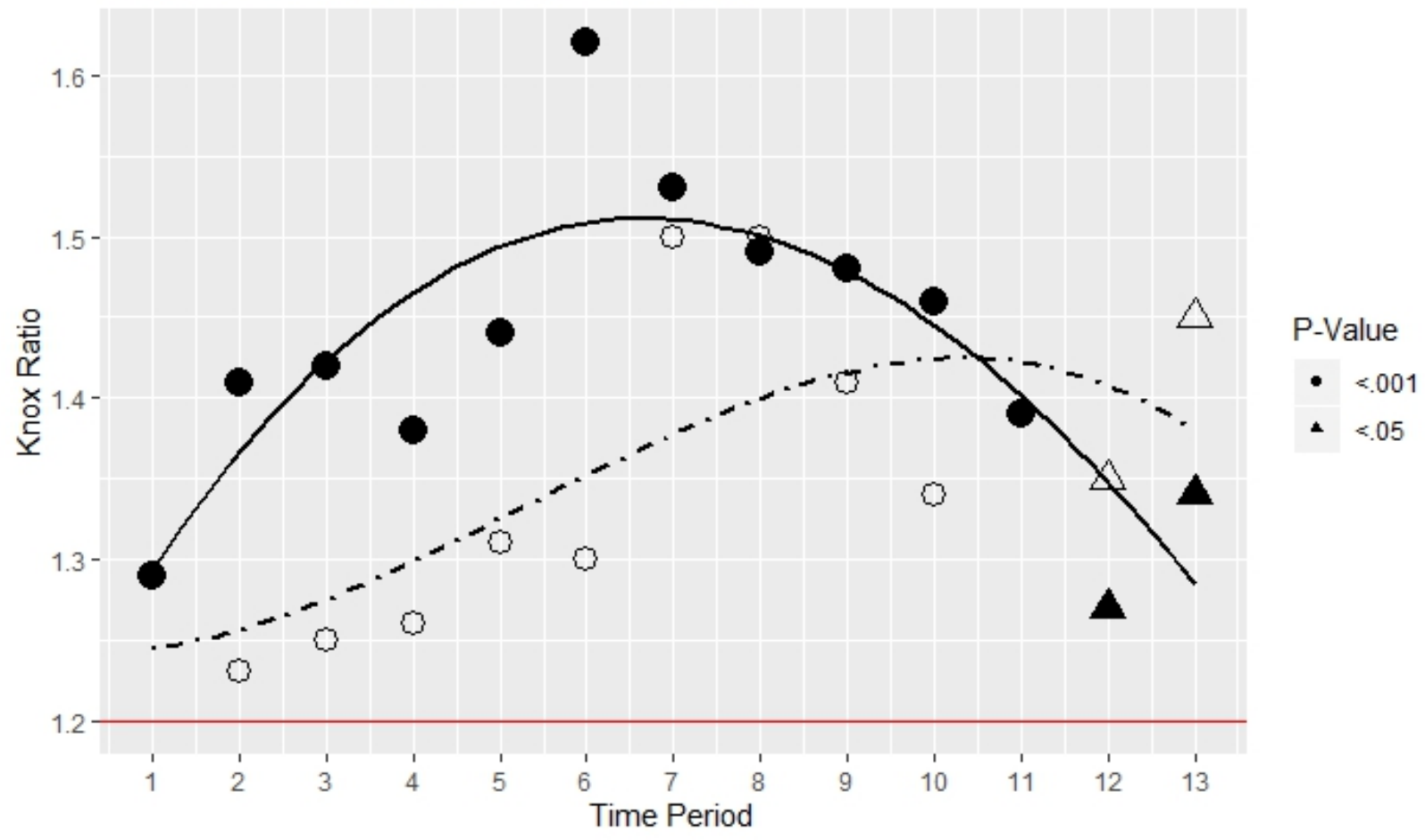

*Solid line is 2 days \& 4 blocks and Checkered line is 4 days \& 3 blocks

**Solid Red Line represents Knox Ratio $=1.20$

The 4 day \& 3 blocks space-time band displayed minimal temporal instability and the lowest mean risk of future robberies (Knox Ratio $=1.35)$, representing a $35 \%$ increased risk of robbery. In addition, it also had the narrowest range (1.50-1.23) and corresponding range width (Range Width $=.27$ ), making it the most stable in terms of effect size. However, the 4 day \& 3 blocks space-time band was tied for the lowest proportion of significant time periods where significance held at p-value $<.001$ of all the space-time bands (23.08\%). When relaxing the significance standard, to $\mathrm{p}$ value $<.05$ all time periods exhibited significant near repeat crime patterns, suggestive of limited stability in significance. Figure 3 shows a relatively stable trend where risk is decreasing over time but is clearly different from the Stable - Increasing trend observed at 2 days \& 4 blocks.

\section{DISCUSSION AND CONCLUSION}


Like Hoppe \& Gerell (2019), the current study provides limited support for the temporal stability of identified near-repeat crime patterns. Our findings support each of our three research hypotheses, and correspondingly have three primary implications for the near-repeat literature.

To address the first two hypotheses, we employed a longitudinal design to track any fluctuations in near-repeat crime risk as well as the reliability of the identified patterns over time. We found that a third (two out of six) of near-repeat patterns do not exhibit temporal stability in effect size or significance. Then, using our temporal stability measures and visualizations of risk trends, we were able to group these observed trends into typologies of temporal stability based on the similarity of their characteristics. We found four distinct groups of typologies that were easily discernible. These identified typologies provide further nuance to the discussion of temporal stability of near repeat crime patterns and help to identify near-repeat crime patterns that are best suited to inform police interventions.

Using our stability measures, we identified two space-time bands where near-repeat crime patterns exhibited Unstable trends ( 1 day \& same location and 1 day and 2 blocks). In these two space-time bands, temporal stability was lacking both in effect size and the reliability of reported effect size over the two-year period. This contrasted with the study findings on a whole, as a large majority (71 out of 78) of the time periods across all space-time bands found significant near-repeat patterns at the pvalue <.05 level. In this sense, temporal instability is highly concentrated among spacetime bands. We deemed only one space-time band to be truly stable in terms of reported risk and reliability ( 1 day $\& 1$ block). The remaining space-time bands exhibited Stable characteristics given our stability measurements but when visualized show clear trends of either Increasing or Decreasing levels of risk over time. Therefore, few space-time bands exhibit truly stable and reliable near repeat crime patterns without discernible trends in reported risk.

Based on our findings, near-repeat analyses conducted on study periods of at least two years may exhibit temporal instability. This contrasts with the findings from the literature concerning the longitudinal study of hot spots that found temporal stability of hot spot crime patterns (Braga et al. 2010; Braga et al. 2011; Groff et al. 2010; Weisburd et al. 2009; Weisburd et al. 2004). Relatedly, crime prevention strategies informed by near-repeat analyses have reported mixed or negative results (Groff \& Taniguchi, 2019; Johnson et al., 2017), unlike those that employ hot spots analyses (Braga et al. 2014). One potential reason for this lack of effectiveness may be focusing 
scarce police resources to account for risk identified in space-time bands that lack temporal stability, specifically those that exhibited moderate to severe temporal instability (Unstable typology). In our analysis, some space-time bands exhibited more temporally stable levels of risk and significance than others. A crime prevention strategy that allocates time and prevention outreach equally across all space-time bands where risk was observed, without examining the pattern for temporal stability, would lead to a misallocation of resources. This is important in the context of the study setting of Newark, NJ, as researchers have recently combined near-repeat analysis with risk terrain modeling measures of at-risk environments for the purpose of identifying micro-level places where crime prevention resources should be concentrated throughout the city (Garnier, Caplan, \& Kennedy, 2018). Our results suggest that such analyses should emphasize the space-time bands that have exhibited consistent and temporally stable levels of near repeat offending risk when considering which places should receive treatments. Temporal stability of near-repeat patterns can be confirmed using the framework we employed in this study.

As an example, the 1-day \& 1 block space-time band would be the most suitable candidate for an intervention due to the stable levels of effect size and significance over the length of the study, suggesting that this pattern would continue into the future, without intervention. This finding further suggests that risk of near repeat is highly temporally and spatially proximate to the originator crime and would necessitate a similar concentration of resources aimed at prevention. In contrast, the near-repeat crime pattern identified in this study at 1 day \& 2 blocks exhibited severe temporal instability and would be relatively unsuitable for such an intervention due to the unpredictable fluctuations in risk. Adding an additional space-time band to account for also reduces the concentrated nature of the intervention and implies a more diffuse distribution of police resources.

Taking our example further, expanding an intervention out to 1-day \& 2 blocks would drastically increase the area police resources would need to cover and lead to a relatively diffuse allocation pattern compared to focusing on the more stable spacetime band (1-day \& 1 block). Applying this to Newark, NJ, where the average street block is 137.77 meters long, a canvassing strategy where police go door to door informing residents of a near repeat event risk (much like in Operation Swordfish that is the focus of Johnson et al. 2017) based on the risk of near repeat crime within 1 day $\& 1$ block of the original event requires three square blocks of coverage or .171 square kilometers. By widening the canvassing area to account for the Unstable space-time band ( 1 day $\& 2$ blocks), as there was an exhibited risk of near repeat event in the two- 
year study, the canvassing area increases by 178\% (an additional .304 square kilometers). This increase in area is especially problematic when accounting for the fact that each new incident that has been identified as having the potential of a near repeat event requires this type of canvassing. Over the length of a year-long intervention this could lead to a substantial increase in canvassing area. However, even when considering only Stable space-time bands, we found that not all stable near repeat patterns are alike and suitable for intervention. Our findings suggest there are noticeable differences among the more stable temporal patterns in terms of fluctuations in exhibited risk over time that was seemingly stable until visualized.

In addition to observed differences between Stable and Unstable typologies, we identified two additional subgroups of Stable trends that exhibited a discernible increase or decrease in exhibited risk over time. Figure 3 is a visualization of the Stable -Decreasing and Stable - Increasing space-time bands (2-day \& 4 blocks and 4 day $\& 3$ blocks). These trends among the 2 day $\& 4$ blocks and 4 day $\& 3$ blocks spacetime bands may relate to a different phenomenon, and may be complementary trends, suggestive of the movement of crime in time and space. Within environmental criminology this movement of risk may be caused by a lack of easily perceived opportunities among robbery offenders which explains the difference in distances they are willing to travel and the longer times between originator and near-repeat events. Such behavior has been previously described as "foraging" among the study of burglars (Johnson et al. 2009) and suggests a similar phenomenon may also extend to robbery offenders. The decrease in risk over time to places less proximate to the originator crime, in this instance, may be explained by the nature of crime to be highly concentrated in place (Weisburd 2015), leading to fewer opportunities the farther an offender gets from the originator crime. The study of burglars may also inform the spatial and temporal distribution of robbery crimes due to the concentrated nature of near repeat events, suggestive of similar or the same offenders as has been found in previous studies on burglary (Bernasco 2008). However, it is still unclear whether chain robberies that may exhibit as near repeat events are by same or similar offenders as the "boost" hypothesis would suggest or due to readily perceptible area characteristics as per the "flag" hypothesis, though robbery chains are typically short (Haberman \& Ratcliffe 2012), suggesting time limited opportunities or short criminal careers.

Future studies using this framework would be greatly beneficial in developing a more complete understanding as to the extent of temporal stability in near-repeat crime patterns. For example, expanding to previously studied crime types with a history of 
exhibiting near-repeat patterns, like burglary, motor vehicle theft, or arson. Due to it being outside of the scope of the current paper, further studies could provide more nuance into whether different types of robbery exhibit different levels of temporal stability.

\section{REFERENCES}

Andresen, Martin A., Malleson, Nick., Steenbeek, Wouter., Townsley, Michael., and Vandeviver, Christophe (2020). Minimum geocoding match rates: an international study of the impact of data and areal unit sizes. International Journal of Geographic Information Science. https://doi.org/10.1080/13658816.2020.1725015

Bediroglu, Gamze., Bediroglu, Sevket., Colak, Ebru H., Yomralioglu, Tahsin. (2018). A crime prevention system in spatiotemporal principles with repeat, near-repeat analysis and crime density mapping: case study Turkey, Trabzon. Crime \& Delinquency, Vol 64 (14), 1820-1835.

Bernasco, Wim. (2008) Them again? Same-offender involvement in repeat and nearrepeat burglaries. European Journal of Criminology. Vol. 5(4), 411-431.

Block, S., \& Fujita, S. (2013). Patterns of near-repeat temporary and permanent motor vehicle thefts. Crime Prevention and Community Safety, 15, 151-167.

Braga, A., Papachristos, A., \& Hureau, D. (2010). The concentration and stability of gun violence at micro places in Boston, 1980-2008. Journal of Quantitative Criminology, $26,33-53$.

Braga, A., Papachristos, A., \& Hureau, D. (2014). The effects of hot spots policing on crime: An updated systematic review and meta-analysis. Justice Quarterly, 31, 633-663.

Braga AA, Hureau DM, Papachristos AV (2011) The relevance of micro places to citywide robbery trends: a longitudinal analysis of robbery incidents at street corners and block faces in Boston. Journal of Research in Crime \& Delinquency 48(1):7-32.

Briz-Redon, Alvaro., Martinez-Ruiz, Francisco., Montes, Francisco. (2019).

Reestimating a minimum acceptable geocoding hit rate for conducting a spatial 
analysis. International Journal of Geographical Information Science. https://doi.org/10.1080/13658816.2019.1703994

Bowers, K., \& Johnson, S. (2004). Who commits near-repeats? A test of the boost explanation.

Western Criminology Review, 5, 12-24.

Braithwaite, Alex R., Johnson, Shane D. (2012). Space-time modeling of insurgency and counterinsurgency in Iraq. Journal of Quantitative Criminology. Vol. 28(1), 31-48. Doi: $\underline{10.1007 / \mathrm{s} 10940-011-9152-8}$

Chainey, S., \& da Silva, B. (2016). Examining the extent of repeat and near-repeat victimization

of domestic burglaries in Belo Horizonte, Brazil. Crime Science, Vol. 5, 1-10.

Chainey, S., \& Ratcliffe, J. (2005). GIS and crime mapping. London: Wiley

Curman, Andrea S. N., Andresen, Martin A., Brantingham, Paul J. (2015). Crime and place: a longitudinal examination of street segment patterns in Vancouver, BC. Journal of Quantitative Criminology. Vol. 31, 127-147.

Eck, John., \& Weisburd, David. (1995). Crime and Place: Crime Prevention Studies. Criminal Justice Press. Police Executive Research Forum.

Farrell, Graham., \& Pease, Ken. (1994). Domestic disputes and residential burglary in Merseyside 1988-90. The British Journal of Criminology. Vol. 34 (4), 487-498.

Garnier, Simon, Caplan, Joel, \& Kennedy, Leslie (2018). Predicting dynamical crime distribution from environmental and social influences. Frontiers in Applied Mathematics and Statistics, 30.

Glasner, Philip., Leitner, Michael. (2016). Evaluating the impact, the weekday has on near-repeat victimization: a spatio-temporal analysis of street robberies in the city of Vienna, Austria. International Journal of Geo-Information. doi:10.3390/ijgi6010003 Groff, Elizabeth., Weisburd D, Yang S (2010) Is it important to examine crime trends at a local "micro" level? A longitudinal analysis of street to street variability in crime trajectories. Journal of Quantitative Criminology. Vol. 26(1):7-32 
Groff, Elizabeth., Taniguchi, Travis. (2019). Using citizen notification to interrupt nearrepeat residential burglary patterns: the micro-level near-repeat experiment. Journal of Experimental Criminology. doi.org/10.1007/s11292-018-09350-1

Grubb, J., \& Nobles, M. (2016). A spatiotemporal analysis of arson. Journal of Research in Crime and Delinquency. Vol. 53, 66-92.

Grubesic, T., \& Mack, E. (2008). Spatio-temporal interaction of urban crime. Journal of Quantitative Criminology. Vol. 24, 285-306.

Haberman, C., \& Ratcliffe, J. (2012). The predictive policing challenges of near-repeat armed street robberies. Policing, A Journal of Policy and Practice. Vol. 6, 151-166. Hino, Kimihiro., Amemiya, Mamoru. (2019). Spatiotemporal analysis of burglary in multifamily housing in Fukuoka City, Japan. Cities. Vol. 90, 15-23.

Hoppe, Laura., \& Gerell, Manne. (2019). Near-repeat burglary patterns in Malmo: Stability and change over time. European Journal of Criminology. Vol 16(1), 3-17.

Johnson, Derek. (2013). The space/time behavior of dwelling burglars: finding nearrepeat patterns in serial offender data. Applied Geography. Vol. 41, 139-146.

Johnson, S., Bernasco, W., Bowers, K., Elffers, H., Ratcliffe, J., Rengert, G., \& Townsley, M. (2007). Space-time patterns of risk: A cross national assessment of residential burglary victimization. Journal of Quantitative Criminology. Vol. 23, 201-219. Johnson, S., \& Bowers, K. (2004). The burglary as clue to the future: The beginning of prospective hot spotting. European Journal of Criminology. Vol. 1, 237-255.

Johnson, Shane D., Davies, Toby., Murray, Alex., Ditta, Paul., Belur, Jyoti., Bowers, Kate. (2017). Evaluation of operation swordfish: a near-repeat target-hardening strategy. Journal of Experimental Criminology. Vol. (13), 505-525.

Johnson, S., Summers, L., \& Pease, K. (2009). Offender as forager? A direct test of the boost account of victimization. Journal of Quantitative Criminology. Vol. 25, 181-200. 
Knox, George. (1964). Epidemiology of childhood leukaemia in Northumberland and Durham. British Journal of Preventive Social Medicine. Vol. 18, 17-24.

Lockwood, B. (2012). The presence and nature of a near-repeat pattern of motor vehicle theft. Security Journal. Vol. 25, 38-56.

Loeffler, Charles., Flaxman, Seth. (2018). Is gun violence contagious? A spatiotemporal test. Journal of Quantitative Criminology. Vol. (34), 999-1017.

Melo, Silas Nogueira., Andresen, Martin A., Matias, Lindon Fonseca. (2018). Repeat and near-repeat victimization in Campinas, Brazil: new explanations from the Global South. Security Journal. Vol 31, 364-380.

Moreto, W., Piza, E., \& Caplan, J. (2014). A plague on both your houses? Risks, repeats, and reconsiderations of urban residential burglary. Justice Quarterly. Vol. 31, 11021126.

Nobles, M., Ward, J., \& Tillyer, R. (2016). The impact of neighborhood context on spatiotemporal patterns of burglary. Journal of Research in Crime and Delinquency, Vol. 53,

pp. 711-740.

Pease, Ken. (1998). Repeat Victimization: taking stock. Home Office Reports: Crime Detection and Prevention Series. Paper (90).

Piza, Eric L., \& Carter, Jeremy G. (2018) Predicting Initiator and Near-repeat

Events in Spatiotemporal Crime Patterns: An Analysis of Residential Burglary and Motor Vehicle Theft. Justice Quarterly, 35:5, 842-870, DOI:

10.1080/07418825.2017.1342854

Ratcliffe, J., \& Rengert, G. (2008). Near-repeat patterns in Philadelphia shootings. Security Journal. Vol. 21, 58-76.

Ratcliffe, J. (2004). Geocoding crime and a first estimate of a minimum acceptable hit rate. International Journal of Geographical Information Science. Vol. 18, 61-72. Ratcliffe, J. (2009). Near-repeat calculator (Version 1.3). Philadelphia, PA; Temple 
University; Washington, DC: National Institute of Justice.

Rossmo, D. (2000). Geographic profiling. Washington, DC: CRC Press.

Sherman LW, Gartin PR, Buerger ME (1989) Hot spots of predatory crime: routine activities and the criminology of place. Criminology. Vol. 27(1):27-56

Short, Martin B., D’Orsogna, Maria R., Brantingham, P. Jeffrey., Tita, George E. (2009). Measuring repeat and near-repeat burglary effects. Journal of Quantitative Criminology. Vol. 25(3), 325-339.

Steenbeek, W. (2018). Near Repeat. R package version 0.1.0.

URL: https://github.com/wsteenbeek/NearRepeat

Sturup, J., Rostami, A., Gerell, M., \& Sandholm, A. (2017). Near-repeat shootings in contemporary Sweden 2011 to 2015. Security Journal. doi:10.1057/s41284-017-0089-y

Sturp, Joakim., Rostami, Amir., Gerell, Manne. (2019). Explosive violence: a nearrepeat study of hand grenade detonations and shootings in urban Sweden. European Journal of Criminology. DOI: 10.1177/1477370818820656

Townsley, M., Johnson, S., \& Ratcliffe, J. (2008). Space-time dynamics of insurgent activity in Iraq. Security Journal. Vol. 21, 139-146.

Townsley, M., Homel, R., \& Chaselin, J. (2003). Infectious burglaries. A test of the near repeat hypothesis. British Journal of Criminology. Vol. 43, 615-633.

Turchan, Brandon., Pizzaro, Jesenia M., Grubb, Jonathan., McGarrell, Edmund F. (2019). Arson in an urban setting: a multi-event near-repeat chain analysis in Flint, Michigan. Security Journal. DOI: 10.1057/s41284-018-0155-0

Wang, Zengli., \& Liu, Xuejun. (2017). Analysis of Burglary Hot Spots and Near-Repeat victimization in a large Chinese city. International Journal of geo-information. Vol. 6(148). DOI:10.3390/ijgi6050148

Weisburd, David. (2015). The Law of Crime Concentration and the Criminology of Place. Criminology. Vol. 53(2), pp.133-157.

Weisburd, David., Bushway, S., Lum, Cynthia., Yang S (2004) Trajectories of crime at places: a longitudinal study of street segments in the City of Seattle. Criminology. 42(2):283-322 
Weisburd, David., Morris NA., Groff, Elizabeth. (2009) Hot spots of juvenile crime: a longitudinal study of street segments in Seattle, Washington. Journal of Quantitative Criminology. 25(4):443-467

Wells, William., Wu, Ling., Ye, Xinyue. (2012). Patterns of Near-repeat gun assaults in Houston. Journal of Research in Crime and Delinquency. Vol. 49(2), 186-212.

Wheeler, Andrew P., Worden, Robert E., McLean, Sarah J. (2016). Replicating groupbased trajectory models of crime at micro-places in Albany, NY. Journal of Quantitative Criminology. Vol (32), 589-612.

Youstin, Tasha J., Nobles, Matt R., Ward, Jeffrey T., Cook, Carrie L. (2011). Assessing the generalization of the near-repeat phenomenon. Criminal Justice and Behavior. Vol. 38 (10), 1042-1063.

Weisburd, David. (2015). The law of crime concentration and the criminology of place. Criminology. Vol. 53(2). https://doi.org/10.1111/1745-9125.12070

Zhang, Yan., Zhao, Jihong., Ren, Ling., Hoover, Larry. (2015). Space-time clustering of crime events and neighborhood characteristics in Houston. Criminal Justice Review.Vol.40 (3), 340-360.

\section{Footnotes}

1. Census Bureau American Community Survey (ACS) 2015 estimates. $\_$

2. FBI Crime in the United States Reports for years 2015 and $2016 \boxminus$

3. FBI Crime in the United States Report for $2016 \leftrightarrows$

4. Differences in between UCR robbery totals and NPD provided records stem from the classification of robberies. NPD internally classifies crime types based upon the primary motive of the offenders. For example, while the UCR would report the forceful taking of property resulting in a victim's injury (e.g. a pedestrian is hit in the face with a gun before an armed robber flees) as an aggravated assault, internal NPD records would classify such an event as a robbery given the context. The NPD maintains such a classification scheme to maintain the validity of their internal analysis products. Crime analysts looking for robbery patterns, for example, would miss an important data point if the aforementioned event were classified as an aggravated assault. $\leftrightarrows$ 